\title{
Tewipack baut neues Logistikzentrum
}

Die Tewipack Uhl GmbH investiert zwei Millionen Euro in den Bau eines 2000 Quadratmeter großen Logistikzentrums in Althengstett. Hier sollen nach dem Einzug im September 2013 auch neue Arbeitsplätze geschaffen werden.

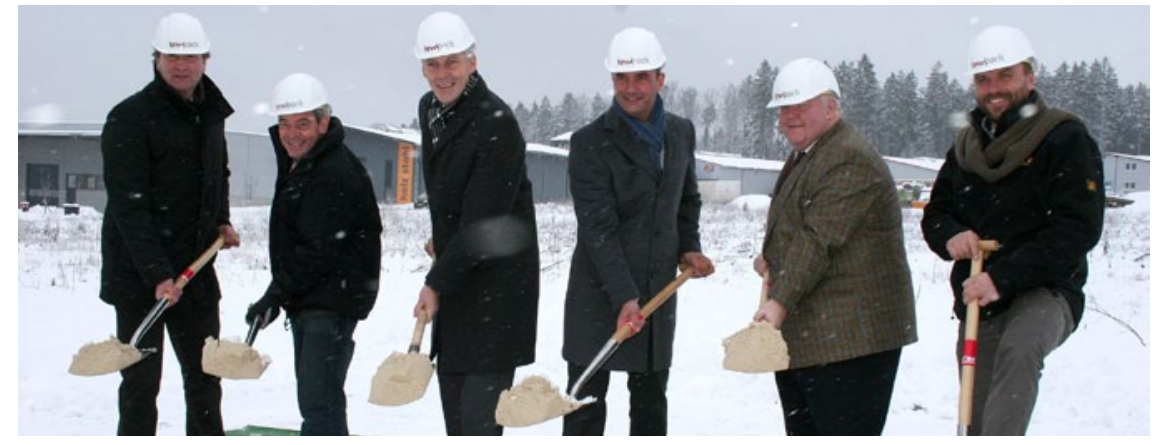

Spatenstich für das neue Tewipack-Logistikzentrum in Althengstetter Gewerbegebiet „Im Unteren Ried“ mit (von links): IHK-Hauptgeschäftsführer Martin Keppler, Bürgermeister Dr. Clemens Götz, Landrat Helmut Riegger, tewipack-Geschäftsführer Alexander Uhl, Hans Neuweiler (stellvertretender Vorstandsvorsitzender der Sparkasse Pforzheim Calw) und Architekt Ulrich Böttinger. (Foto: k-w)

S eit Gründung vor 40 Jahren ist der sen, bilanzierte Geschäftsführer Alexander Uhl anlässlich des Spatenstichs mit
Landrat und Bürgermeister. Deshalb sei das Lager des Unternehmens, das bereits in dritter Generation geführt wird, zu klein geworden. Vor 20 Jahren sei die
Belegschaft in den Neubau an der Industriestraße umgezogen, der Hauptstandort bleiben werde. Das neue Logistikzentrum wird mit Hochregalen und einem speziellen Kühllager ausgestattet, in dem besonders sensible Klebstoff-Systeme und Klebebänder aufbewahrt werden. Es schaffe die notwendige Fläche, so Uhl, damit sich das Unternehmen weiterentwickeln könne. Die Kunden profitierten künftig von noch schnelleren Lieferzeiten, da Tewipack durch das zehnmal größere Lager in der Lage sein werde, mehr Artikel aus seinem sehr breiten Sortiment namhafter Hersteller zu bevorraten.

Tewipack ist nicht nur Lieferant von Klebstoff-Systemen und Klebebändern, sondern begleitet auch den jeweiligen Produktionsprozess bis zu Serienreife.

\section{Handbuch Klebtechnik 2012 auch als eBook verfügbar}

Das „Handbuch Klebtechnik 2012“ bietet Anwendern die Möglichkeit, sich einen schnellen und zielgerichteten Überblick über die Struktur der gesamten deutschen Klebstoffindustrie zu verschaffen und steht seit einiger Zeit auch virtuell als eBook zur Verfügung.

$\mathrm{D}$ ieses deutschsprachige Werk wurde 2012 bereits zum zehnten Mal vom Industrieverband Klebstoffe e. V. gemeinsam mit der Redaktion adhäsion auf den neuesten Stand gebracht und demonstriert unter anderem die Liefer- und Leistungsfähigkeit von circa 140 auf dem Gebiet der Klebtechnik aktiven Unternehmen sowie wissenschaftlichen Instituten. Außerdem enthält es wichtige Fakten über die Klebstoffindustrie sowie den Verband - einschließlich der neuesten gesetzlichen Vorschriften, europäischen Normen sowie Prüfverfahren und statistische Übersichten. Dieses mehr als 300 Seiten starke Buch erleichtert das Recherchieren rund um das Thema Kleb- und Dichtstoffe.

Die Printversion kann gegen eine Schutzgebühr von 25,90 Euro per Mail angefordert werden: adhaesion@ springer.com

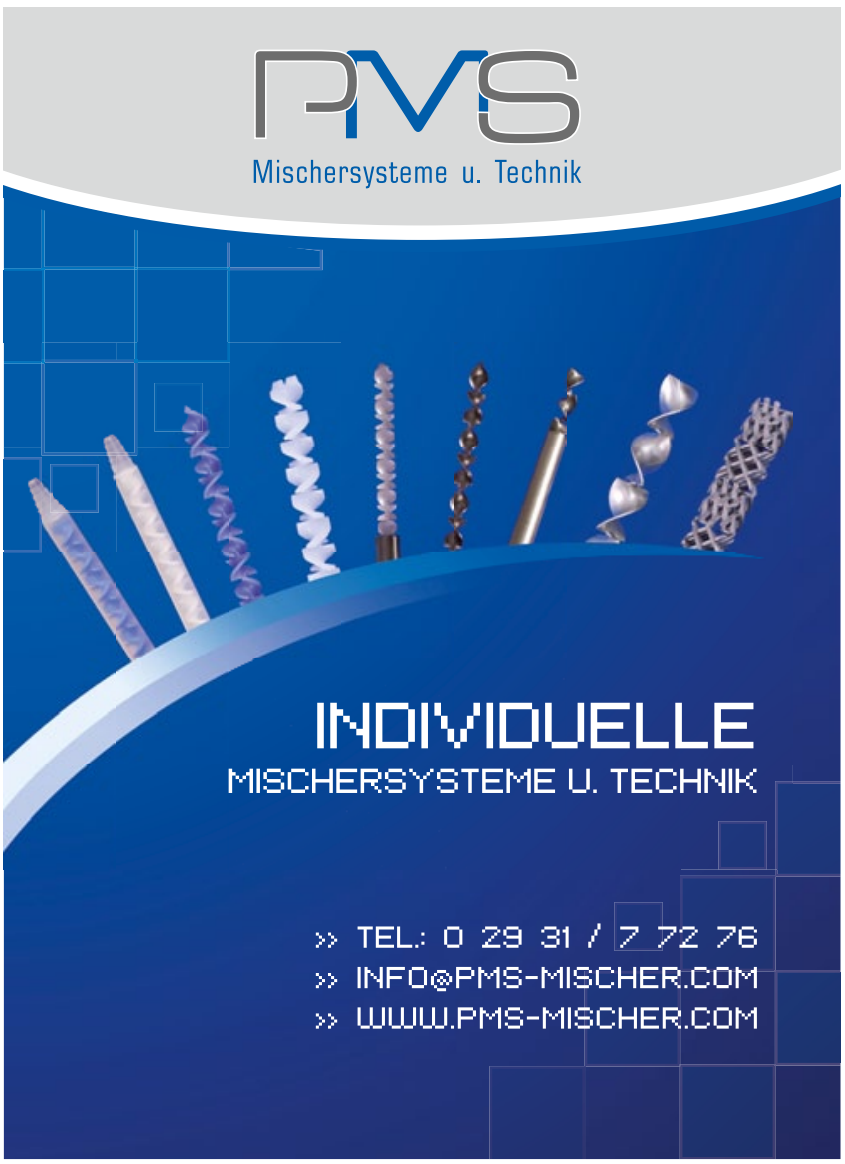

